\title{
EDITORIAL \\ The establishment of Neurosurgical Focus: personal reflections by the Editors-in-Chief
}

\author{
Martin H. Weiss, MD, ${ }^{1}$ and William T. Couldwell, MD, PhD² \\ ${ }^{1}$ Department of Neurosurgery, University of Southern California, Los Angeles, California; and 2Department of Neurosurgery, \\ Clinical Neurosciences Center, University of Utah, Salt Lake City, Utah
}

\section{Dr. Weiss, Editor-in-Chief 1996-2016}

In late 1995, during my tenure as Chairman of the Journal of Neurosurgery (JNS) Editorial Board, it became apparent that a number of distinguished scientific journals (e.g., Journal of Biological Chemistry) had begun to establish websites providing access to online editions of their monthly journal publications. These online editions were password protected, giving access only to subscribers who preferred "electronic reading" to the traditional paper journal. I discussed this with Dr. John Jane Sr., who was the Editor-in-Chief of the JNS at that time, with the thought that we might initiate an online edition of the JNS that could include 1) immediate online publication of any accepted manuscript; 2) monthly online publication of the full edition of JNS contemporaneous with the printed journal; and 3) no additional charge to subscribers, allowing free and easy access to worldwide readership.

At that time, I thought we might ultimately offer our subscribers the option of receiving their monthly journal via print, electronically, or both. For those who chose to read their journal solely electronically, this might constitute cost savings with respect to printing costs. However, Dr. Jane believed that the electronic format had not yet matured to the point where we could provide first-class service to our subscribers via that format, and there was a potential issue of sustaining advertising revenue in the event that readership of the print edition of the JNS should decline significantly. So that proposal was put on the back burner for consideration at some future date.

In recognition of the growing impact of the internet, Dr. Jane suggested that we consider an alternative option for electronic publication by the JNS that would 1) establish our presence on the internet and 2) provide us with additional experience in the realm of electronic publication that would ultimately enable a smoother transition to electronic publication by the JNS. After discussion with the JNS Editorial Board (Fig. 1), we decided to create an entirely new journal that would be published only elec- tronically with a format that would not compete directly with the print JNS. This exciting new option would allow us to provide this publication in an open format, becoming one of the first electronic major medical journals free to be read by all.

Rather than compete with the JNS for uninvited manuscript submissions, we decided that the new journal would consist of invited manuscripts on a specific, preapproved topic for each month. We selected the name Neurosurgical Focus to reflect this objective. Early on, the monthly topic would be overseen by an Editorial Board member for that month; the job of this individual would entail peer review of all submitted manuscripts, so that the new journal would indeed represent a peer-reviewed publication.

In concept, we thought that each monthly issue would constitute a peer-reviewed chapter on a given topic. The short time from manuscript submission to electronic publication would ensure the timeliness of the information. As such, our objective was to publish a series of different monthly topics related to neurosurgery that would emulate chapters in a textbook with the additional benefit that each "chapter" consisted of up-to-date, peer-reviewed material. After several years, each of the topics could be revisited as needed, ensuring that the material would always be contemporaneous with existing neurosurgical practice and scientific advances. We decided to replace the Editorial Board with topic editors who have interest and experience in the specific monthly topic. We appointed a monthly editorial board, who would serve as primary and secondary reviewers for the submitted manuscripts related to the particular issue, a procedure that continues to this day.

In July 1996, we proudly published our first issue of Neurosurgical Focus, "Pituitary Disease and Endocrine Problems," which consisted of 10 articles and additional Editor's Perspective commentaries by experts in this field. Figure 2 shows the framed preview cover of the April 1996 issue, presented to me as a gift from Drs. Rutka and Jane. Note their personal inscriptions: "Marty, the unbelievable 


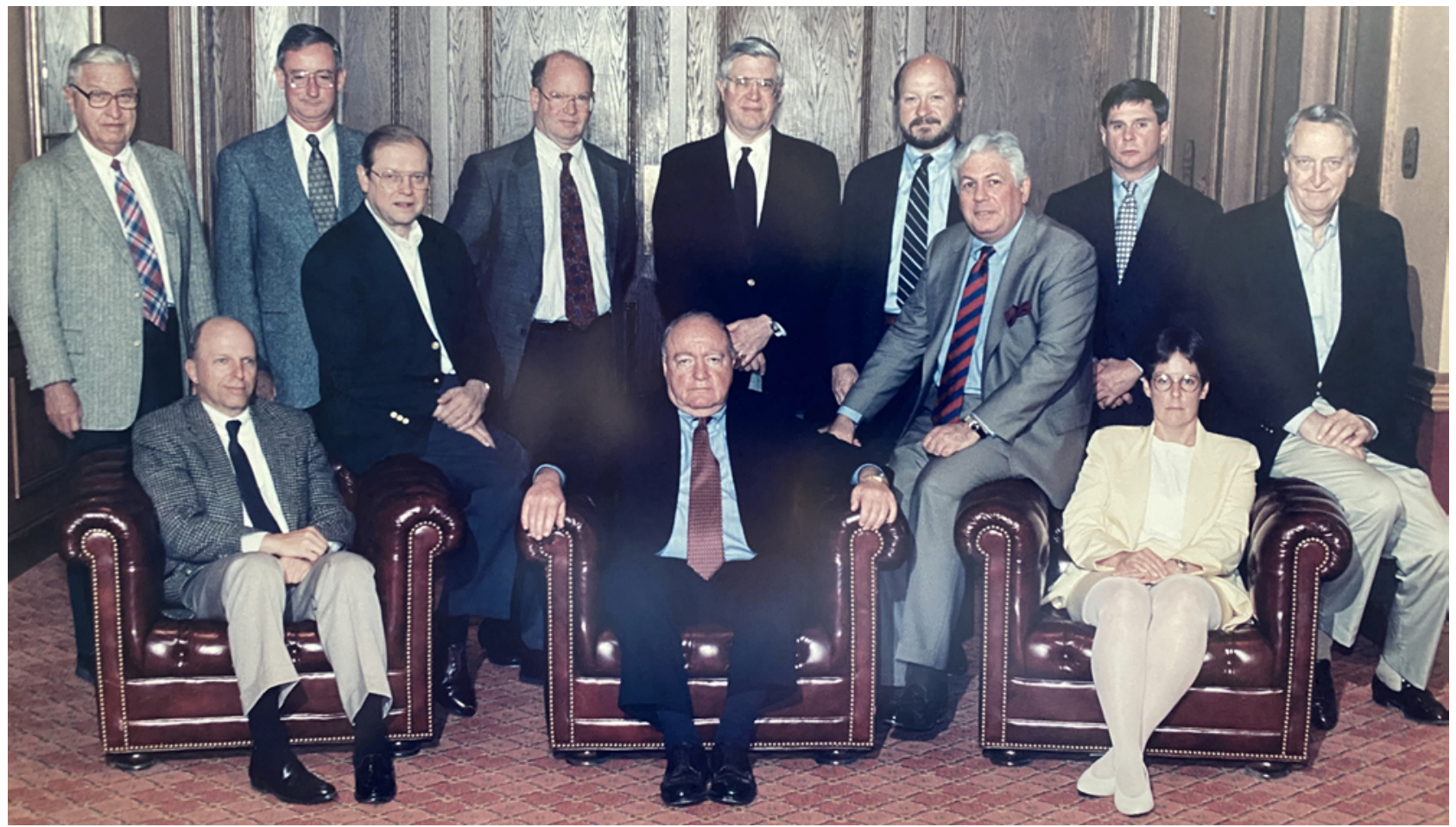

FIG. 1. JNS Editorial Board members. Front row: Martin Weiss, John Jane Sr., Ms. Keller Kaufman-Fox; back row: William Collins, Austin Colohan, Julian Hoff, Charles Hodge, Robert Wilkins, Edward Oldfield, Robert Ratcheson, Ralph Dacey, John Girvin. (C)1996 American Association of Neurological Surgeons.

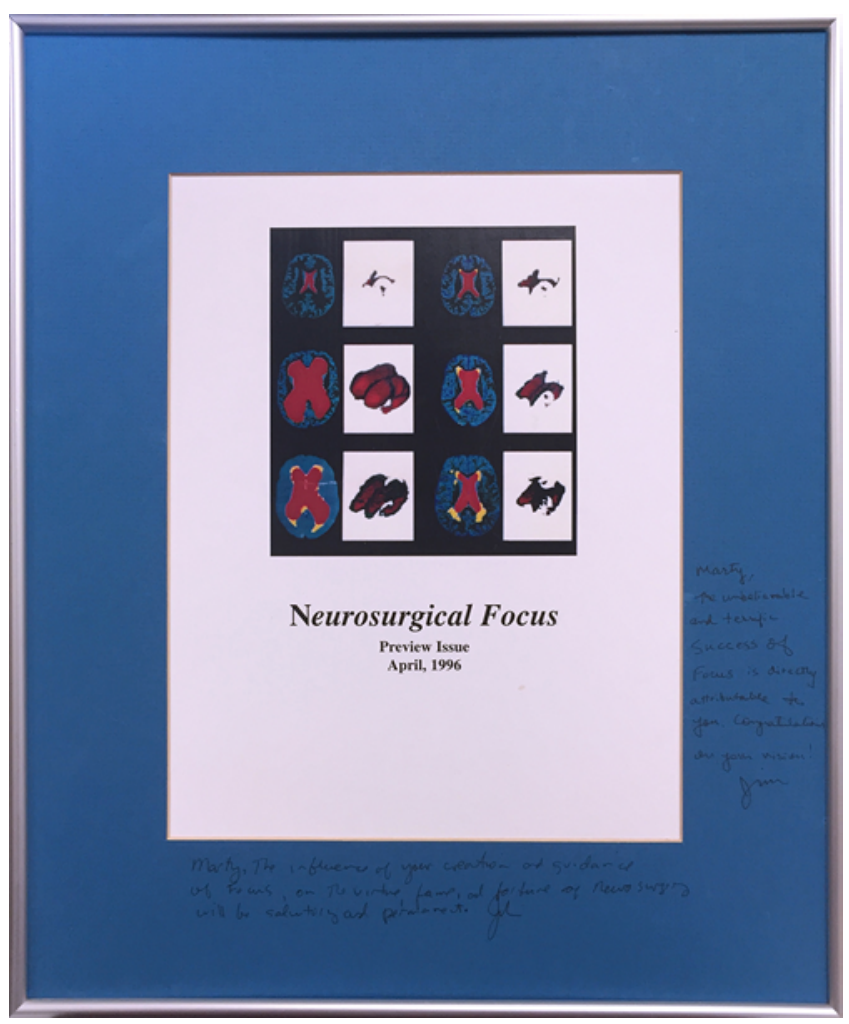

FIG. 2. Framed preview of the April 1996 cover. @1996 American Association of Neurological Surgeons. and terrific success of Focus is directly attributable to you. Congratulations on your vision! Jim" and "Marty, the influence of your creation and guidance of Focus, on the virtue, fame, and fortune of neurosurgery will be salutary and permanent. John"

Shortly after publication, we recognized that this innovative program would enable us to offer continuing medical education (CME) credit to AANS members. We invited authors of manuscripts to submit a list of questions and answers related to their articles for CME credit. These are entered into the AANS portal, currently enabling members to earn 3 hours of category I CME monthly, a significant service to our membership.

\section{Dr. Couldwell, Editor-in-Chief 2016-present}

As a result of the prescient idea of Drs. Weiss and Jane and the Editorial Board members at the time, Neurosurgical Focus has well served the role in which it was conceived and has continued value for the readership of the Journal of Neurosurgery Publishing Group (JNSPG). Furthermore, rather than just "reviewing" a current timely neurosurgical topic chosen monthly, the journal has progressively encouraged and published novel clinical and translational research studies relevant to the particular topic, publishing only the very best review papers submitted (the majority of the reviews that are submitted are currently not accepted). To this end, the majority of the papers published now are adding to our established knowledge, and we have accordingly witnessed the 2020 impact factor of the journal rise to 4.047 , documenting the clinical 

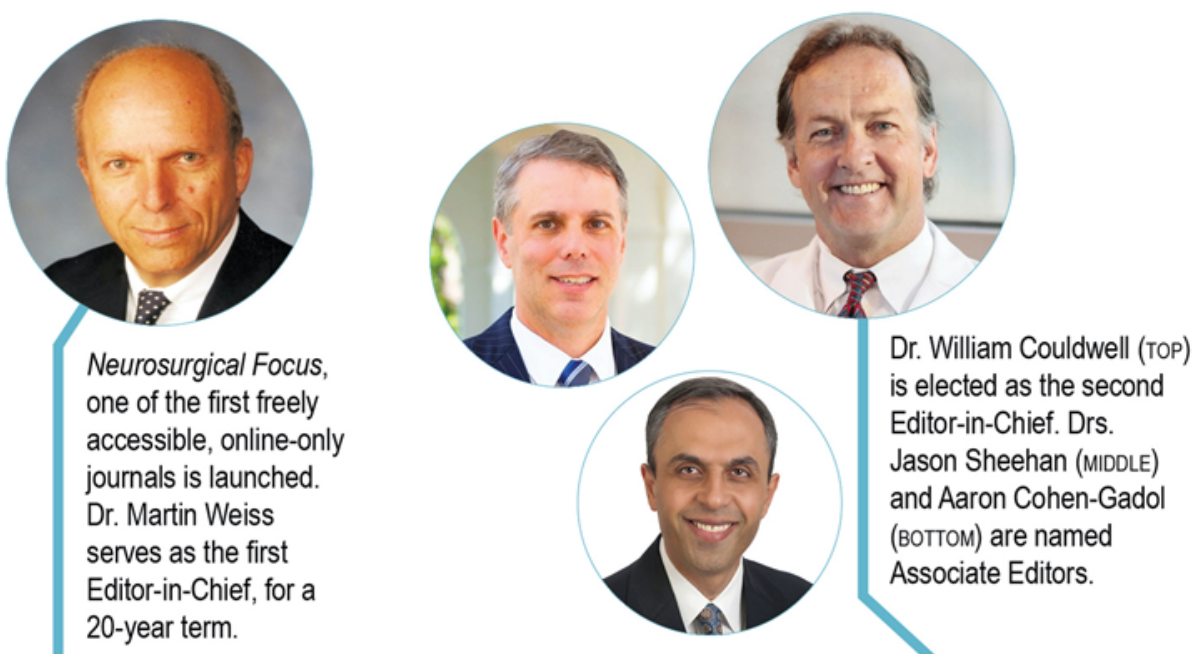

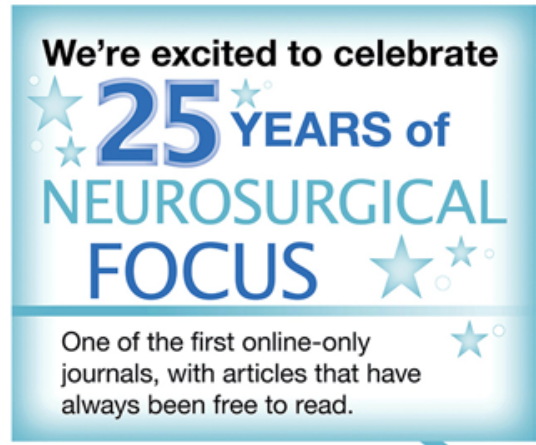

Neurosurgical Focus celebrates its 25 th year of publication; its highest impact factor to date is achieved at 4.047.

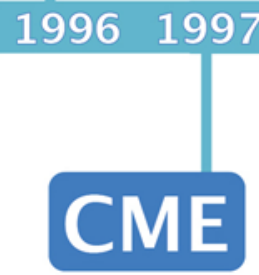
Continuing medical education credits are offered to AANS members for selected monthly articles.

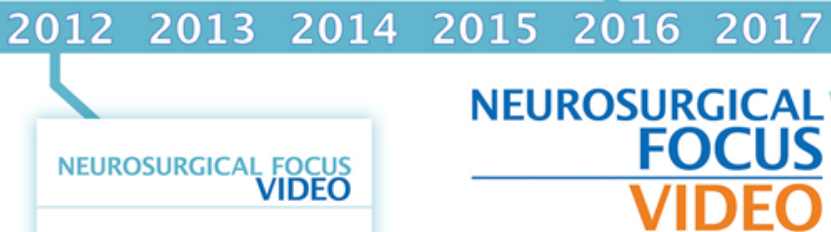
Neurosurgical Focus: Video becomes an independent quarterly journal, featuring videos with accompanying abstracts and transcripts.

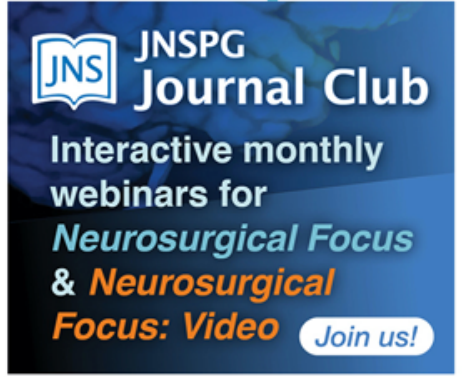
$201820192020 \quad 2021$

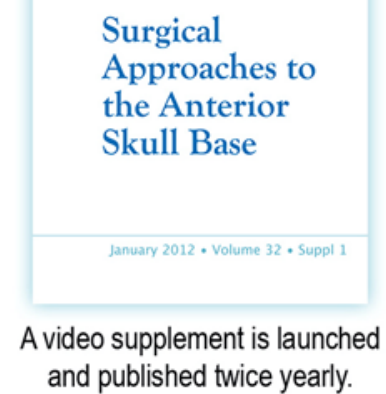
An interactive Journal Club is established for both Neurosurgical Focus (monthly) and Neurosurgical Focus: Video (quarterly).

FIG. 3. Timeline of major accomplishments from 1996 to present time. Photographs reprinted with permission of the copyright holders: Dr. Martin Weiss, Dr. Jason Sheehan, Dr. Aaron Cohen-Gadol, and the Department of Neurosurgery, University of Utah for the photograph of Dr. William Couldwell.

impact of the published articles as evidenced by citations in the literature.

Within the past 2 years, we have established our surgical video journal, Neurosurgical Focus: Video, as its own entity, which has had an overwhelming recognition with a large number of submissions and is well on its way to becoming a major vehicle for demonstrating state-of-the-art technical surgical innovation, again using a topic-oriented format. Neurosurgical Focus: Video is currently being published quarterly, but we anticipate it being published every other month in the near future. Both Neurosurgical Focus and Focus: Video have striven to employ international and gender-diverse editorial board members to broaden the involvement of talented and productive neurosurgeons within our global community. We also continually welcome suggestions from the worldwide readership for diverse and timely topics that represent the rapidly changing aspects of our neurosurgical practice. In 1996, 210 manuscripts were submitted to Neurosurgical Focus, and this number has continued to increase over the years.
In 2020, we received nearly 700 manuscript and video submissions for Neurosurgical Focus and Focus: Video.

In 2020, we initiated a monthly Journal Club format to underline particularly high-impact articles from each issue that can be experienced in a video or audio format; these sessions encapsulate the important clinical pearls derived from each of these articles that are changing practice.

None of this would be possible without the outstanding assistance of Associate Editors Drs. Aaron CohenGadol and Jason Sheehan, who manage the process of the rapidly growing number of submissions to both journals. We acknowledge the superb JNSPG staff, notably, Margie Shreve, who has been the foundational administrative resource since the inception of Focus and has personally contributed immensely to the success of both of the journals by continuously streamlining our process improvement from manuscript and video submission to publication.

We look forward to the next quarter century of growth, capitalizing on technology improvements that have been 
iteratively employed to create advancements that enhance our educational experience in a multimedia format. Forthcoming initiatives will include a rapid-response editorial section that will enable interchange and dialogue regarding published manuscripts and also represent a forum for newsworthy contributions. Taken together, we strive to further establish the JNSPG journals as the authoritative source for our dynamic specialty, enabling more rapid communication and utilizing our online technology to its fullest advantage.

We show a timeline of major accomplishments from 1996 to the present time in Fig. 3.

\section{Acknowledgments}

We thank Kristin Kraus for editorial assistance.

\section{Correspondence}

Martin H. Weiss: weiss@med.usc.edu.

\section{INCLUDE WHEN CITING}

DOI: 10.3171/2021.8.FOCUS21469. 